Revista de Estudios Histórico-Jurídicos

[Sección historia del derecho público]

XL (Valparaíso, Chile, 2018)

[pp. 141 - 165]

\title{
HISTORIA Y DERECHO INTERNACIONAL
}

[History and International Law]

\author{
Oscar Olivares Jatib \\ Universidad de los Andes, Santiago, Chile* \\ Fernando Pérez Godoy \\ Pontificia Universidad Católica de Chile**
}

\section{RESUMEN}

El presente artículo analiza los actuales giro histórico y giro imperial en la investigación jurídica internacional con el objetivo de repensar el rol de la disciplina histórica en el entendimiento contemporáneo del derecho internacional. Para ello acudimos a las contribuciones de la historia global, historia de los imperios, de los encuentros, estudios culturales y crítica postcolonial del derecho.

Palabras Clave

Derecho internacional - Historia Giro imperial - Postcolonialismo.
Abstract

The following paper analyses the historical and imperial turns in the legal international scholarship with the goal of rethinking the function of the history in the actual understanding of international law. For this, we would want to employ the contributions of the approaches from global history, history of encounters, cultural studies, postcolonial legal critic and history of empires.

KeYwords

International Law - History - Imperial Turn - Postcolonialism.

RECIBIDO el 2 de abril de 2018 y ACEPTADO el 2 de junio de 2018

* Licenciado en Historia, Abogado y Magíster en Derecho, Universidad Católica de Valparaíso. Estudiante de Doctorado en Derecho, Universidad de los Andes, Chile. Profesor de Derecho del Trabajo de la Universidad de las Américas. Email: olivaresjatib@gmail.com.

** Doctor phil. Universidad de Mainz, Alemania. Proyecto Fondecyt N³ 3180115, Pontificia Universidad Católica de Chile. Email: fernandoperezgodoy@gmail.com. 


\section{INTRODUCCIÓN}

En 1908 Lassa Oppenheim establecía que la historia del derecho internacional era tierra virgen esperando a sus cultivadores ${ }^{1}$. Peter Haggenmacher, más de un siglo después, reconoce que los historiadores tradicionales del derecho internacional han sido largamente vistos como amateurs marginales ${ }^{2}$. Comúnmente es citada aquí la expresión alemana: la historia del derecho internacional sería Spross der Völkerrechtslehrer-el vástago de los teóricos del derecho de gentes-. Como veremos en este artículo, hoy somos testigos del llamado historical turn de la investigación jurídica internacional, giro metodológico que reposiciona la historia no solo en el área teórica sino también en el quehacer del derecho internacional. Básicamente la disciplina histórica no sería más un campo ornamental de los internacionalistas, su lugar en la construcción, entendimiento y dirección del actual orden jurídico internacional debe ser repensada ${ }^{3}$. Este es el primer objetivo de nuestro estudio. ¿Pero por qué la historia?, ¿qué tendría que decir hoy la historia a la racionalidad y formalismo jurídico? En este sentido el giro a la historia y al recurso de la c o n t e x t u a li z a c i ó n son inentendibles según nuestro parecer sin tomar en cuenta el llamado imperial turn del derecho internacional. Ambas perspectivas metodológicas son objeto de nuestro estudio, tratando de descifrar sus principales argumentos, así como entender sus fundamentos teóricos a la luz de las recientes contribuciones hechas por la historia global del derecho, historia de los imperios, de la cultura y los estudios jurídicos críticos postcoloniales.

\section{HistORIA CANÓNICA}

La historiografía liberal o canónica del derecho internacional se ha concentrado en el proceso de secularización del pensamiento jurídico ${ }^{4}$, la codificación o Verrechtlichung del derecho internacional y en la construcción de un sistema de Estados soberanos regulado por un rule of law que se superpone al estado de todos contra todos hobbesiano de anarquía internacional ${ }^{5}$. Esta visión evolutiva y genealógica marcada por la meta narrativa de p r o gres os y a va n c e s del

\footnotetext{
${ }^{1}$ Oppenheim, Lassa, The Science of International Law: Its Task and Method, en American Journal of International Law, 2 (1908), p. 313.

${ }^{2}$ Haggenmacher, Peter, Avant propos, en Kadelbach, Stefan; Kleinlein, Thomas y RothIsIGKEIT, David (eds.), System, Order, and International Law: The Early History of International Legal Thought from Machiavelli to Hegel (Oxford, 2017), p. ix.

3 "International law in its beginnings appears to a large extent as an offshoot of early modern political and moral philosophy at grips with the Romanistic and Canonistic jus commune; and philosophy has ever since had an important share in its development". HAGGENMACHER, Peter, cit. (n 2), p. x.

${ }^{4}$ HaAkonssen, Knud, Natural law and moral philosophy: from Grotius to the Scottish Enlightenment (Cambridge, 1996). Hochstrasser, Tim, Natural Law Theories in the Early Enlightenment, (Cambridge, 2000). GIERKE, Otto, Natural Law and the Theory of Society 1500 to 1800 (trad. ingl., Boston, 1960). VAn Gelderen, Martin y SkInNer, Quentin (eds.), Republicanism: Republicanism and constitutionalism (Cambridge, 2002). HuNTER, Ian, The Secularisation of the Confessional State, The Political Thought of Christian Thomasius (Cambridge, 2007).

${ }^{5}$ JoAs, Hans y KNÖBL, Wolfgang, Kriegsverdrängung: ein Problem in der Geschichte der Sozialtheorie (Frankfurt am Main, 2008), pp 30-34. DuchHARdT, Heinz y SchnetTGer,
} 
derecho internacional es comúnmente conocida dentro de la historiografía legal como paradigma westfaliano y en el campo de la historia intelectual retrotrae a la influencia de una serie de juristas principalmente centro europeos, siendo Hugo Grocio y su De iure belli ac pacis de 1625 padre fundador ${ }^{6}$. Configurada como una historiografía de h i t o s, los tratados de Münster (30.1.) y Osnabrück (2425.10) de 1648 no solo fueron Reichgrundgesetz, sino también fundamentales para la historiografía dogmática por gestar principios esenciales del sistema westfaliano como la secularización de las relaciones internacionales, razón de Estado, igualdad de soberanía, balance de poder, tolerancia religiosa (ius reformandi) y soberanía territorial (ius territorii et superioritatis) ${ }^{7}$. Los tratados mencionados habían puesto fin en el imperio germano a la Krieg aller Kriege, la guerra de todas las guerras, hablamos de la Guerra de los Treinta Años, seguramente el episodio más traumático en la historia germana a la luz de los 500 años de la Reformation ${ }^{8}$ y este 2018 a 400 años del estallido de tal guerra ${ }^{9}$. El imperio germano fue precisamente el espacio donde los poderes aliados se enfrentaron sin tregua generando una catástrofe que quedará impregnada en la memoria colectiva alemana como un trauma social producto del peso histórico de la derrota, la desintegración y la destrucción ${ }^{10}$. El recuerdo de la guerra será entonces el mejor garante de la paz westfaliana. Al contrario, 1648 para los demás países beligerantes será consagrado como el mito del origen de los Estados soberanos nacionales, un recuerdo de victoria alimentado por los nacientes nacionalismos.

En World Order, un escrito clásico en el área de las relaciones internacionales, Henry Kissinger reconoce justamente que el orden mundial y su sistema de reglas no solo tiene un origen europeo -civilización cristiana- y su fundamento en la Paz de Westfalia ${ }^{11}$. Al ser este orden normativo de carácter procedimental -no

Matthias, Barock und Aufklärung (5ª ed., Göttingen, 2015). HorN, Nobert, Einführung in die Rechtswissenschaft und Rechtsphilosophie (München, 2012), pp. 142-144.

6 Grotius, Hugo, De iure belli ac pacis libri tres (Paris, 1625).

7 Van Creveld, Martin, The Rise and Decline of the State (Cambridge, 1999), p. 198. Kissinger, Henry, Diplomacy, (New York, 1994), p. 58. Held, David, La democracia y el orden global del Estado moderno al gobierno cosmopolita (trad cast., Barcelona, 1997), pp. 43-49. WALZER, Michael, Tratado sobre la Tolerancia (trad. cast. Barcelona, 1998), p. 25. MEINECKE, Friedrich, Idea de la razón de Estado en la edad moderna, (trad. cast., Madrid, 1997).

${ }^{8}$ Stephan, Cora, Die deutsche Kriegsangst beginnt mit dem Jahr 1618, en Welt 14.06.2013, [visible en internet: www.welt.de/geschichte/article117121459/Die-deutsche-Kriegsangst-beginnt-mit-dem-Jahr-1618.html ] Williams, George, La reforma radical (trad. cast., Ciudad de México, 2005). Koselleck, Reinhart, Crítica y crisis. Un estudio sobre la patogénesis del mundo burgués (trad cast., Madrid, 2007), pp. 47-49.

${ }^{9}$ WILson, Peter, Der Dreißigjährige Krieg: Eine europäische Tragödie (Stuttgart, 2017).

10 "Ninguna pluma sería capaz de describir y hacernos comprender la inseguridad de la vida y de la propiedad por entonces, la terrible dureza de la consigna cuius regio eius religió [...] Sólo los ignorantes se pueden reír del acento sagrado que para los hombres de aquellos días tuvieron las palabras religión natural, ilustración, tolerancia y humanidad. En ellas respira el aliento agónico de un mundo que sucumbe bajo el peso impotente de las confesiones". Dilthey, John W., Hombre y Mundo en los siglos XVI y XVII (trad. cast. México, 1978), p. 108

${ }^{11}$ KISSINGER, Henry, World Order: Reflections on the Character of Nations and the Course of History (New York, 2014), p. 15. 
sustantivo-, se ha transformado con el tiempo en global (global westphalian system) y común al resto de las civilizaciones (Islam, China) ${ }^{12}$. Del sistema westfaliano, explica Kissinger, Estados Unidos es hoy su garante en pos del principio de defensa de la democracia ${ }^{13}$. Para el siglo XVII, el derecho internacional -ius gentium europeaum - absorbió los principios desarrollados en medio de la crisis internacional europea que arrastraron a los beligerantes a las conferencias de paz en $1648^{14}$. Como veremos, lo importante, es que en la formulación de estas reglas el resto de civilizaciones no tuvo injerencia, aun cuando producto de la influencia de las revoluciones en comunicación -expediciones, imprenta-, las naciones extra europeas no solo conocerán tal sistema y normas, sino, las utilizarán en sus procesos de descolonización y luchas de liberación nacional ${ }^{15}$. La idea de equilibrio de poder y de una multiplicidad de unidades política-culturales y religiosas autónomas, pero al mismo tiempo contrapeso de las otras (Estados soberanos) se contraponía no solo al orden unitario mundial del emperador romano y el papado (teoría medieval de las dos espadas), sino, explica Kissinger, al concepto jerárquico y universal del emperador Chino y el califato musulmán (posterior emperador otomano) ${ }^{16}$. El riesgo del dominio imperial universal de una civilización justifica para el politólogo americano la legitimidad del sistema westfaliano ${ }^{17}$. La pluralidad político confesional de Europa y su orden de diversidad cultural en mucho descansarían en el sistema de balance de $\operatorname{poder}^{18}$ y en una base de reglas acordadas del derecho común que bloqueaban la supremacía de un poder sobre el mundo ${ }^{19}$. Para nuestro estudio es importante rescatar que para Kissinger el derecho internacional, ideado por Grocio en su versión moderna, tendría su corazón en los tres tratados westfaliano ${ }^{20}$ y su razón de ser, así como de las negociaciones diplomáticas, es finalmente forjar el deseo de evitar una guerra total por la supremacía.

Para nuestro análisis tales tratados y jurisprudencia son importantes además porque establecieron las pautas, temas y perspectivas de investigación histórica del orden jurídico internacional moderno. El Estado soberano aparecerá desde entonces en la historiografía genealógica como el único sujeto legítimo del orden del derecho de gentes ${ }^{21}$. En el plano de política externa primarán derechos soberanos ahora reconocidos como exclusivos del Estado territorial como: ius ad bellum,

12 'The genius of this system, and the reason it spread across the world, was that its provisions were procedural, not substantive. If a state would accept these basic requirements, it could be recognized as an international citizen able to maintain its own culture, politics, religion, and internal policies, shielded by the international system from outside intervention". KISSINGER, Henry, cit. (n. 11), p. 65.

13 Ibíd., p. 23.

14 Truyol y Serra, Antonio, La sociedad internacional (Madrid, 1994), p. 35.

15 Kissinger, Henry, cit. (n. 11), pp. 23-27.

${ }^{16}$ Ibíd., pp. 19-21.

17 Ibíd., p. 65.

18 Ibíd., p. 77.

19 Truyol y Serra, Antonio, cit. (n. 14), pp. 32-36.

${ }^{20}$ Kissinger, Henry, cit. (n. 11), p. 63.

${ }^{21}$ Cassese, Antonio, States: Rise and Decline of the Primary Subjects of the International Community, en Fassbender, Bardo y Peters, Anne (eds.), The Oxford Handbook of International Law (Oxford, 2012), pp. 49-69. 
derecho de intervención y ocupación, reconocimiento de soberanía, así como el principio "faciendi inter se et cum exteris foedera pro sua cuiusque conservatione ac securitate singulis statibus" 22 .

Pero en suma este es un relato estándar, en mucho forjado por la historiografía jurídica europea de los siglos XVIII y XIX. Incluso Kant establecía que la idea del derecho de gentes requiere la separación de muchos Estados vecinos independiente unos de otros ${ }^{23}$, siendo tal vez la más común de las definiciones remontada a la experiencia de 1648. Sin embargo, en la celebración de sus 350 años, la Friedenschluss de Westfalia ha sido desmitificada y con ello mucho del entendimiento del derecho internacional que se nos ha heredado ${ }^{24}$. Si nos hemos preguntado por el rol de la historia en el derecho internacional, encontramos aquí un claro ejemplo. La investigación histórica jurídica de los últimos años llevó a deconstruir el significado original construido sobre el tratado internacional de 1648 como un moderno sistema de aseguramiento de $\mathrm{paz}^{25}$. A 400 años del estallido de la guerra, la pesquisa histórica no sólo ha llenado los conocidos vacíos de investigación pre y post evento, sino, además, invitó a repensar cultural, simbólica, lingüística y medialmente al derecho internacional y las prácticas jurídicas teorizadas desde entonces $^{26}$. Para Lesaffer los principios de igualdad soberana (recién confirmados legalmente en la paz de Utrecht), neutralidad religiosa o balance de poder no se encuentran en los tratados de Paz de Westfalia ${ }^{27}$. Por su lado Asbach establece que la Guerra de los Treinta Años fue llevada a cabo no por Estados modernos, sino por Estados en formación, sustentando su conocida tesis que fue justamente el carácter no completo, deficiente o embrionario del Estado en la época moderna lo que llevó a la Bellizität del sistema de paz europeo ${ }^{28}$. Detrás del sistema westfaliano de Estados regulado por un orden normativo internacional (l'droit de gens

${ }_{22}$ Citados en Stolleis, Michael, Geschichte des öffentlichen Rechts in Deutschland (München, 1988), p. 225.

23 "Die Idee des Völkerrechts setzt die Absonderung vieler voneinander unabhängiger benachbarter Staaten voraus". KANT, Immanuel, Zum Ewigen Frieden, I, 2. La tripartición romana del derecho (desde el Corpus Civiles, Digestas e Intitutiones de Justiniano, s. VI d.c.) separaba derecho de gentes, derecho natural y derecho civil. La sistematización es de Ulpiano, recepcionada por la Escolástica y Tomas de Aquino hasta Francisco Suárez. Con Kant pasan a ser tratados como derecho internacional, principio general libertad y derecho estatal respectivamente. MAUREIRA PACHECO, Max, La tripartición romana del derecho y su influencia en el pensamiento jurídico de la época Moderna, en Revista Estudios Históricos-Jurídicos, 28 (2006), pp. 269-288.

${ }^{24}$ DuchHARdT, Heinz, 1648 - Das Jahr der Schlagzeilen. Europa zwischen Krise und Aufbruch (Köln / Weimar / Wien, 2015). WesTPHAL, Siegrid, Der Westfälische Frieden (München, 2015).

25 "Los padres de los instrumentos de 1648 quisieron crear, con total determinación, un ordenamiento pacifico duradero y a largo plazo; éste fue el motivo de que se regulara mucho más de lo que habia sido el objeto real de la guerra y de que los cambios introducidos en el imperio se pusieran bajo la garantía de potencias extranjeras, integrándose asi en el derecho internacional". DUCHHARDT, Heinz, Época del Absolutismo (trad. cast., Madrid, 1992), p. 25. BöDEKER, Hans Erich von, Strukturen der deutschen Frühaufklärung 1680 - 1720 (Göttingen, 2008).

${ }^{26}$ ESPENhorst, Martin y DuCHHARDT, Heinz (eds.), Frieden übersetzen in der Vormoderne. Translationsleitungen in Diplomatie, Medien und Wissenschaft (Göttingen, 2012).

${ }^{27}$ LesSAFFer, Randall, Peace treaties from Lodi to Westphalia, en ÉL MISMO (ed.), Peace Treaties and International Law in European History (Cambridge, 2004), pp. 9-11.

${ }^{28}$ BuRKHARDT, Johannes, Wars of States or Wars of Stat-Formation?, en AsBaCH, Olaf y 
d'Europa), más bien se encontraría una serie de conexiones dinásticas regidas por derecho consuetudinario y privado propias de la compleja formación del Estado como proceso socio cultural ${ }^{29}$. Lo cierto es que en la estructura constitucional imperial postwestfaliana se hallaran formas diplomáticas de comunicación y regulaciones del derecho de gentes, pero unidas a otros ámbitos del derecho como derecho constitucional, derecho de sucesión y derecho feudal, que en su conjunto formaban la estructura jurídica del orden europeo ${ }^{30}$. La presunta dualidad entre soberanía interna y externa, así como la despersonalización del Estado, la idea del derecho disuelta de relaciones personales, burocratización, concentración, modernización, racionalización, institucionalización y monopolio de poder, han sido también desmontadas como categorías únicas de análisis en la historiografía jurídica internacionalista marcada por el paradigma de la modernidad ${ }^{31}$. Más que una efectiva normativa común, el derecho de gentes se encontraba en una compleja red, entramado a distintas fuentes del derecho y compartido por distintos poderes, dinastías y principados europeos, entre quienes primaban relaciones patriarcales tradicionales de poder, poderes locales, corporativos y aristocráticos ${ }^{32}$. La imagen de un ius gentium como un derecho entre Estados independientes e iguales ${ }^{33}$, que superaba las estructuras universalistas del papado e imperio, es por tanto a lo menos inexacta o vinculada principalmente al acaecer del entramado de poder europeo $^{34}$. Como veremos, el problema radica en que el concepto de Estado ha

SCHRÖDER, Peter (eds.), War, the State and International Law in Seventeenth-Century Europe (Ashgate, 2010), pp. 18-26.

${ }^{29}$ La discusión sobre la realización de la norma desde una perspectiva cultural de lo político: LandweHr, Achim, Diskurs-Macht-Wissen. Perspektiven einer Kulturalgeschichte, Kulturgeschichte des Politischen, en Archiv für Kulturgeschichte, 85 (2003). NICKLAS, Thomas, Macht-Politik-Diskurs. Möglichkeiten und Grenzen einer Kulturgeschichte des Politischen, en Archiv für Kulturgeschichte, 86 (2004). STOLLEIS, Michael, Normdurchsetzung bei Policeyordnungen der frühen Neuzeit, en RUPPERT, Stefan y VeC, Miloš (eds.), Ausgewählte Aufsätze und Beiträge (Frankfurt am Main, 2011), pp. 226-227. LANDWEHR, Achim, "Normdurchsetzung" in der Frühen Neuzeit? Kritik eines Begriffs, en Zeitschrift für Geschichtswissenschaft, 48 (2000), p. 149.

${ }^{30}$ STEIGER, Heinhard, Rechtliche Strukturen der Europäischen Staatenordnung 1648-1792, en Zeitschrift für ausländisches öffentliches Recht und Völkerrecht (Zä̈RV), (1999), p. 609.

${ }^{31}$ FreIST, Dagmar y Asch, Ronald G, Staatsbildung als kultureller Prozess Strukturwandel und Legitimation von Herrschaft in der Frühen Neuzeit (Wien, 2005), p. 8. STOLLBERG-RILINGER, Barbara, Das Heilige Römische Reich Deutscher Nation. Vom Ende des Mittelalters bis 1806 (München, 2006), p. 17.

${ }^{32}$ FreIst, Dagmar y Asch, Ronald G., cit. (n. 31), p. 5.

${ }^{33}$ Zacarias Zwantzig establece esta igualdad soberana: "so ist es [...] nunmehro über ein saeculum dahin gekommen / daß kein König oder gecröntes Haupt dem andern in rang und praecedentz etwas nachgeben / weniger ihm nachgehen will. Dann es wollen selbige den rang unter sich nicht mehr nach der antiquität ihrer Königreiche / königlichen herrlichkeit und namens/ noch nach der puissance ihrer reiche oder vielheit und vermögen ihrer lande / sondern bloß nach der königlichen autorität / würde und souveränität abmessen als welche keine distinction leidet". ZWANTZIG, Zacharias, Theatrum praecedentiae (Berlin, 1705), I, p. 12.

34 "Es war keinesfalls selbstverständlich, daß eine stabile politisch-rechtliche Ordnung Europas auf der Grundlage der souveränen, gleichgeordneten Staaten entstehen würde". STEIGER, Heinhard, cit. (n. 30), p. 613. 
sido usado para describir cualquier actor del derecho internacional en el pasado sin serlo necesariamente ${ }^{35}$.

Por su parte la historiografía intelectual tradicional se ha detenido con especial interés en las querellas y conexiones entre iusracionalistas y escolásticos, entre juristas católicos y protestantes ${ }^{36}$, entre aquellos que dialogaban con las ciencias exactas (Scienza nuova) y el método científico, y aquellos filósofos ligados a Aristóteles y Santo Tomas. No menos discusión tuvo lugar con los enfrentamientos entre naturalistas y grocianos en el siglo XVIII y en el siglo XIX entre universalistas y voluntaristas ${ }^{37}$. En la conformación de este relato progresivo el punto de inflexión en el siglo XVIII lo representa la obra de Emer de Vattel. El jurista suizo había superado al neo escolástico y aristotélico Christian Wolff cuando esboza un nuevo derecho de gentes aplicable a la nature des nouveaux sujets: el Estado nación ${ }^{38}$. Luego sintetiza el giro del naturalismo al voluntarismo jurídico cuando establece que "Le Droit des Gens est la Loi des Souverains"39. Para Steiger encontramos la síntesis del pensamiento jurídico internacional, cuando el pensador suizo indica que la guerra según el derecho de gentes se reduce a una guerra pública entre dos naciones soberanas $s^{40}$. En resumen, los internacionalistas modernos apoyados en la herencia jurídica romana y en las nuevas ciencias formaban una $h$ is $t$ o $r$ i a $\mathrm{d}$ e las c o n t r i b u c i o n e s-Beitragsgeschichte-del ius naturae et gentium al proyecto de modernidad jurídica europea. Esta línea historiográfica, representada por ejemplo en la serie de publicaciones y traducciones alemana Bibliothek des deutschen Staatsdenkens o la americana Liberty Fund, hacen, sin embargo, escasa referencia al espacio extra occidental como productor de ideas jurídicas ${ }^{41}$. Más

35 STEIgER, Heinhard, Das ius publicum europaeum und das Andere, a global history approach, en VON ARNAUlD, Andreas (ed.), Völkerrechtsgeschichte(n): historische Narrative und Konzepte im Wandel (Berlin, 2017), p.75.

36 Vallet de Goytisolo, Juan, Metodología de la determinación del derecho (Madrid, 1994). Rodríguez Puerto, Manuel, Modernidad discutida: jurisprudencia frente iusnaturalismo en el siglo XVI (Cádiz, 1998).

${ }^{37} \mathrm{NEFF}$, Stephen, Justice among Nations, a history of international law (Cambridge, 2014), pp. 180-181.

38 “'Ce grand Philosophe a vî que l'application du Droit Naturel aux Nations en Corps, ou aux Etats, modifiée par la nature des Sujets, ne peut se faire avec précision, avec netteté \& avec solidité, qu'à l'aide des Principes généraux \& des notions direc trices, qui doivent la règler; que c'ést par le moyen de ces Principes seuls que l'on peut montrer évidemment, comment, en vertu du Droit Naturel même, les décisions de ce Droit à l'égard des particuliers doivent être changées \& modifiées, quand on les applique aux Etats, ou Sociétes Politiques, \& former ainsi un Droit des Gens naturel et necessaire”. VATTEL, Emer de, Le droit des gens ou principes de la loi naturelle, appliqués à la conduite \& aux affaires des Nations \& des Souverains (London, 1758), Preface, p. XII.

39 "Le Droit des Gens est la Loi des Souverains. C'est pur eux principalement, \& pur leurs Ministres, qu'opn doit l'écrire". VATtel, Emer de, cit. (n. 38), p. XXIII.

40 STEIGER, Heinhard, cit. (n. 30), p. 615.

${ }^{41}$ WolfF, Erik, Grosse Rechtdenker der deutschen Geistesgeschichte (Tübingen, 1951). Hammerstein, Notker y STOLleis, Michael (eds.), Große Staatsdenker in der frühen Neuzeit. (München, 1995). Carpintero Benítez, Francisco, Nuestros prejuicios acerca del llamado derecho natural, en Persona y Derecho: Revista de Fundamentación de las Instituciones Jurídicas y de Derechos Humanos, 27 (1992), pp. 101-112. HinOjosa y NAVEROs, Eduardo, Los precursores españoles de Grocio (Madrid, 1930), pp. 221-236. 
bien, van de una mirada de juristas nacionales a una de Europa como espacio histórico común de comunicación ${ }^{42}$, obviamente visión motivada por el proyecto de la Unión Europea. Juristas globales, periféricos o al menos transoceánicos como lo fueron Heineccius, Vattel, Bluntschli o Wheaton serán solo tema accesorio ante las clásicas obras del pensamiento internacional centro europeo.

En consecuencia, queremos destacar que la forma de normatividad internacional creada desde el siglo XVI hasta Westfalia y luego moldeada en el siglo XVIII bajo la filosofía de la ilustración, el avance del positivismo jurídico, el darwinismo social y el liberalismo político económico, era un derecho exclusivo practicado por los Estados europeos. Para el siglo XIX, tal orden se expresa según Truyol y Serra como un derecho de gentes particular entre las potencias europeas cuya expresión máxima será el sistema de Viena ${ }^{43}$. Steiger explica que independiente del estatus jurídico, de si se trataba de los cantones suizos o de la monarquía francesa, el sultán, o un principado germano, el ius gentium, o los portadores del ius belli ac pacis, eran parte de la republica cristiana, actores del theatrum europeaum ${ }^{44}$. Concuerda Luigi Nuzzo al declarar que la sociedad internacional en el siglo XIX fue una Interessengemeinschaft de Estados cristianos europeos los cuales debido a su c o n c i e n c i a l e g a l c o m ú n crearon un espacio jurídico restrictivo a un grupo selecto de naciones civilizadas ${ }^{45}$. Esta comunidad de intereses estaba abierta a cada Estado el cual adoptase el llamado standard of civilisation y contribuyera a la solidaridad de sus miembros, especialmente en el área económica comercial ${ }^{46}$. El estándar de civilización consistía básicamente en una serie de requisitos culturales normativos exigidos por las grandes potencias centro europeas al resto de las naciones del siglo XIX. Como veremos, la habilidad de las naciones extra europeas de completar estos requisitos será clave en contexto de descolonización de los siglos XIX y XX.

Pero la perspectiva historiográfica eurocéntrica que hemos querido describir tiene su punto más alto en la obra de Carl Schmitt. En Der Nomos der Erde de 1950 el jurista alemán establecía que no existía un orden jurídico internacional fuera del espacio europeo o fuera del ius gentium como expresión del ius publicum europeaum. Cuando Schmitt sustentaba que solo los poderes europeos que tenían la habilidad para convertirse en Estados podían luchar por la Landnahme de espacios libres no europeos ${ }^{47}$, él pensó solo en entidades del viejo continente.

42 Wunderer, Hartmann, Staat und Herrschaft in der Frühen Neuzeit (Stuttgart, 2014), p. 95. SÁNCHEZ-BlanCO, Francisco, La Ilustración y la unidad cultural europea (Madrid, 2013), pp. 46-47.

43 Truyol y Serra, Antonio, cit. (n. 14), p. 40.

44 STEIGER, Heinhard, cit. (n. 30), p. 616.

45 Nuzzo establece con claridad: "Once again, international law was a product of European Christendom whose goals of free trade and the community of nations had been realized thanks to the sense of brotherhood inspired by Christianity". Nuzzo, Luigi, Territory, Sovereignty and the Construction of the Colonial Space, en KosKenniemi, Martti y RECH, Walter y JiménEZ FonseCA, Manuel (eds.), International law and empire: historical explorations (Cambridge, 2016), p. 266

46 Ibíd., p. 265.

47 Schmit, Carl, Der Nomos der Erde im Völkerrecht des Jus Publicum Europeam (Köln, 1950), p. 100 
Ni las naciones no europeas pertenecían al Völkerrechtsordnung, ni el mundo no occidental guiaba y regulaba sus conflictos por algún tipo de rule of law (bellum legale). Tal vez el internacionalista no europeo más leído del siglo XIX, Henry Wheaton, sustentaba justamente que la regulación jurídica internacional de las naciones islámicas del Este con cada una o con los cristianos era algo muy distinto al derecho internacional ${ }^{48}$. En la misma perspectiva el alemán Kalterborn argumentaba en 1847 que otros Estados -los no europeos- tenían relaciones internacionales, pero estas no actuaban sobre la base del derecho "auf der Basis

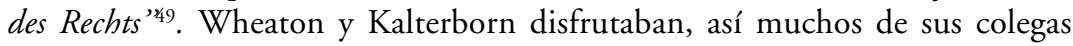
contemporáneos como el venezolano Andrés Bello, de los privilegios de una Völkerrechtsgemeinschaft, es decir, un proyecto nacido de los usos y prácticas de la familia de naciones civilizadas que aseguraba comercio, industria y cultura ${ }^{50}$. Como es conocido, Schmitt vio en la expansión espacial del ius publicum europeaum del siglo XIX el fin de un orden global, más bien el fin de un orden concreto del espacio -konkrete Raumordnung-. Desde el siglo XV el espacio fuera de este orden, América, África, Asia, era un espacio potencialmente de ser tomado legítimamente por el Staatsgebiet europeo ${ }^{51}$. Lógicamente, fuera del espacio concreto normado por el ius publicum europeaum no existía más historia del derecho internacional. Pero desde fines del siglo XIX la expansión europea arrastró esta normatividad fuera de su espacio histórico, creando un universalismo legal y un derecho de naciones que pronto se convertirá, dice Schmitt, en un derecho mundial universal indistinto -unterschiedlos universales Weltrecht- cuyo único objetivo era sustentar el libre comercio para todas las naciones ${ }^{52}$. En este sentido, Schmitt vio que la historia del ius publicum europeaum llegaba a su fin con la expansión imperial europea y sobre todo a principios de siglo XX con el ascenso de Estados Unidos como eje de un orden liberal universal ${ }^{53}$. Pero este nuevo orden representaba a sus ojos finalmente un normativismo vacío (leerer Normativismus) marcado por la pérdida de orden del espacio, la Diffusität y Leere ${ }^{54}$. Para la historiografía jurídica del siglo XIX y principios del XX las culturas jurídicas no europeas serían efectivamente parte de

48 "The Mohammedan nations of the East with each other, and with Christians, is another and very different thing". WHEATON, Henry, Elements of International Law: With a Sketch of the History of the Science (Philadelphia, 1836), p. 145.

${ }^{49}$ Kalterborn von Stachau, Carl, Kritik des Völkerrechts nach dem jetzigen Standpunkte der Wissenschaft (Leipzig, 1847), p. 270.

${ }^{50}$ Bello, Andrés, Principios de derecho de jentes (Valparaíso, 1832), p. 4.

51 SchmitT, Carl, cit. (n. 47), pp. 54-55.

52 Steiger, Heinhard cit. (n. 35), pp. 59-64.

53 Ibíd., p. 62.

${ }^{54}$ El cambio estructural del derecho internacional con la supremacía de Estados Unidos generó según Schmitt que la moral liberal se impone en el orden internacional, siendo la guerra ahora una de expiación y sanción. El orden legal americano era en esencia moralista, volviendo a la situación de la Edad Media europea donde la guerra es entre enemigos morales (cristianos versus infieles), situación superada por la paz Westfalia de 1648 cuyo sistema había desacralizado y secularizado la guerra, limitándola a una entre enemigos públicos, entre soberanos iguales o justus hostis que no diferenciaba entre naciones bárbaras y civilizadas. VAN GELDEREN, Martin, 'Iustitiam non includo': Carl Schmitt, Hugo Grotius and the Ius Publicum Europaeum, en History of European Ideas, 37 (2011), pp. 155-156. Sobre el concepto de revolución planetaria del 
un legal exotism ${ }^{55}$. Como es conocido y en contradicción a la mirada eurocéntrica de Schmitt, la historia del ius gentium europeaum se siguió desarrollando en estos y otros espacios fuera de la comunidad legal europea ${ }^{56}$, generando, como veremos, una serie de h i s t o r i a s paralelas del derecho internacional.

\section{GIRO HISTÓRICO}

Ante la pregunta enunciada sobre el rol de la historia en el actual entendimiento del derecho internacional, B. S. Chimni explica que la historia tiene la función de revelar los conceptos legales que fueron desarrollados en tiempos coloniales y de imperios formales, pero en adelante continúan siendo normativos en el actual derecho internacional ${ }^{57}$. En este mismo sentido, Fassbender y Peters han hablado de un vínculo viviente ${ }^{58}$. También para Orford, afrontando el complejo problema del anacronismo de la investigación internacionalista, el pasado puede ser una fuente actual de obligación. Conceptos y prácticas fueron desarrollados en contextos imperiales, es decir, en contextos no normados por el derecho y más bien forjados por la marcha de los poderes políticos y económicos ${ }^{59}$. La deconstrucción de estas prácticas y conceptos por la ciencia histórica nos conduce entonces a la pregunta por el origen de la legitimidad del discurso jurídico, poniendo en jaque el eurocentrismo, liberalismo, positivismo y Estado centrismo propios de la disciplina. Lesaffer por su parte explica el giro a la histórica como un sudden boom, sustentando la conocida tesis de que en todos los momentos críticos en la historia de las relaciones internacionales, de cambio político o revolucionario, los investigadores no han enunciado como respuestas innovaciones jurídicas, sino han debido mirar atrás, una revisión de la historia de la disciplina, especial-

espacio de Schmitt vs. Derman, Joshua, Carl Schmitt on land and sea, en History of European Ideas, 37 (2011), pp. 186-187.

${ }_{55}$ Ruskola, Teemu, Legal Orientalism. China, The United States, and Modern Law (Cambridge, 2013).

${ }^{56}$ Pérez Godoy, Fernando, Ibero-Amerikanische Zirkulation des protestantischen Natur-und Völkerrechts im 18. und 19. Jahrhunderts (Göttingen, 2016). La teoría del derecho de guerra de Bluntschli y Vattel en Chile, entre otros internacionalistas europeos, fue utilizada para legitimar acciones chilenas durante la Guerra del Pacífico (1879-1884), véase IbarRa Cifuentes, Patricio, La guerra en cautiverio. Los prisioneros de la Guerra del Pacifico (1879-1884) (Santiago, 2017), pp. 24-27. En el mismo sentido para la ocupación de Lima la obra de Achien Mollin Les lois relatives à la guerre selon le droit des gens moderne (Paris, 1872). POLACK, Bruno, El uiltimo virrey del Perú. Patricio Lynch y la ocupación chilena durante la Guerra del Pacifico (Santiago, 2017), pp. 111-116.

${ }^{57}$ Chimni, Bhupinder, Le passé, le présent et Lávenir du droit international, en OufaYAN, Mark (ed.), Droit international et nouvelles approches sur le tiers-monde: entre répétition et renouveau (Paris, 2013), pp. 34-35.

${ }^{58}$ Fassbender, Bardo y Peters, Anne, The Oxford Handbook of the History of International Law (Oxford, 2012), p. 3.

59 "The past, in other words may be a source of present obligations. Similarly, legal concepts and practices that were developed in the age of formal empire may continue to shape international law in the post-colonial era". ORFORD, Anne, The Past as Law or History? The Relevance of Imperialism for Modern International Law, en IILJ Working Paper 2012/2, U of Melbourne Legal Studies Research Paper, 600 (2012), p. 99. 
mente de la fundación del derecho de naciones ${ }^{60}$. Cómo una regla del derecho internacional nace, se desarrolla y gradualmente se reconoce como práctica es un complejo proceso más allá de la mera genealogía de la norma. En consecuencia, la auto descripción del derecho como algo meramente jurídico (sistema de normas) es una imagen occidental que niega finalmente al derecho como fenómeno mult iconceptual.

La historia de los imperios y sus desmembramientos vino por su parte a reformular el espacio histórico y temporal sobre el que se entendía el desarrollo del derecho internacional como una normativa compartida exclusivamente por Estados soberanos ${ }^{61}$. La historia de los imperios, sobre todo el británico ${ }^{62}$ e hispánico, mas la historia global permiten identificar sujetos internacionales que no respondían al paradigma westfaliano de Estados soberanos e instituciones internacionales, es decir, sujetos como los protectorados y formas de poder autónomos, entidades pre coloniales que respondían a órdenes normativos regionales y locales ${ }^{63}$. La historia global ha demostrado cómo en las interacciones transoceánicas de transferencia de conocimiento jurídico y contactos globales aparecen actores no tradicionales que crearon en el tiempo múltiples tipos de normatividades correspondientes a cada época, a una cultura concreta y en un marco específico de civilización. Detrás de ello se encuentra obviamente el fenómeno de la globalización que llevó al choque, encuentro y contacto a culturas jurídicas alejadas y diversas, poniendo de relieve los fenómenos de pluralismo legal y multinormatividad ${ }^{64}$. Steiger explica que la idea de universalidad es una construcción europea que se refleja tanto en la promoción de una idea uniforme de justicia universal como en la meta narrativa de una historia universal. Esta visión monolítica ha sido superada por la historia global, la historia de los encuentros ${ }^{65}$, los entrelazados e intercambios de distintos pueblos y costumbres. En este marco, Europa, su ciencia y sus valores, pero también la historiografía jurídica, han sido interpelados a provincializarse ${ }^{66}$. Así, los valores de Occidente ocupan solo un espacio más en un marco global, en el que prima la investigación de la cultura o contexto cultural del que nace un orden normativo ${ }^{67}$. Aquí los recursos de la historia cultural y la sociología del derecho han

${ }^{60}$ Craven, Matt, Introduction: International Law and Its Histories, en Él MISMO, FiTzMAURICE, Malgosia y Vogiatzi, Maria (eds.), Time, History and International Law (Boston, Leiden, 2007), p. 7.

${ }^{61}$ Osterhammel, Jürgen, The transformation of the world. A global history of the Nineteenth century (trad. ingl., Princeton, 2014), pp. 859-862. Annino, Antonio; Castro Leiva, Luis y Guerra, François-Xavier (eds.), De los imperios a las naciones: Iberoamérica (Zaragoza, 1994). FERnÁNDEZ SebASTIÁn, Javier (ed.), La aurora de la libertad. Los primeros liberalismos en el mundo iberoamericano (Madrid, 2012).

${ }^{62}$ Benton, Lauren y Ford, Lisa, Rage for Order. The British Empire and the Origins of International Law 1800-1850 (Cambridge, Mass., London, 2016).

63 STEIGER, Heinhard, cit. (n. 35), p. 67.

${ }^{64}$ Duve, Thomas, Was ist Multinormativität? - Einführende Bemerkungen, en Rechtsgeschichte - Legal History Rg., 25 (2017) [visible en internet://dx.doi.org/10.12946/rg25/088-101].

${ }^{65}$ Steiger, Heinhard, cit. (n. 35), p. 68-69.

${ }^{66}$ Chakrabarty, Dipesh, Provincializing Europe. Postcolonial Thought and Historical Difference (Princeton, 2008).

67 Véase la serie de publicaciones y conferencias de derecho como cultura del Das Käte 
marcado pauta. No menos la contextualización que utilizase las ciencias históricas de la escuela de Cambridge, principalmente como metodología del estudio del pensamiento político jurídico ${ }^{68}$. En síntesis, el giro a la historia llama a investigar materiales bibliográficos, rutinas institucionales, agendas políticas, presiones e influencias, dinámicas y dramas sociales, así como actividades extra curriculares de los internacionalistas al crear sus obras. Todos estos temas finalmente nos dirigen a la actual historia de la profesión y su ejercicio a nivel global ${ }^{69}$.

No menos útil ha sido la historia global para entender los procesos de comunicación de normas del derecho internacional a través de la adopción, apropiación o traducción de textos europeos fuera del viejo continente ${ }^{70}$. Apoyados en la historia de la circulación de conocimiento y transferencia cultural entre espacios socio culturales geográficamente lejanos encontramos una serie de j u r i s t a s $\mathrm{g}$ l o b a l e s poco estimados por la historiografía. Conjuntamente con la fundación global de cátedras universitarias de derecho internacional, podemos mencionar como paradigmático dentro de la circulación de textos a la obra del jurista suizo Johann Caspar Bluntschli, miembro fundador del Institut de droit international. Su tratado Das moderne Völkerrecht der civilisierten Nationen que data de 1868 experimenta rápidamente un proceso de traducción global. Mientras que en 1870 el tratado aparece en francés, en 1871 es traducido al español en México por Díaz Covarrubias. Luego en Japón aparece en 1876 como Kokuhõ hanron, Hiroyuki Katô trans (Tôkyôfu, Kondõ Keizõ, 1876), en griego en 1874 bajo el nombre Ho diethnes Kodix (Athenai, 1874), al ruso como Sovremennoe mezhdunarodnoe pravo tsivilizovannykh gosudarstv, izlozhennoe v vidie kodeska (Moskva, Indrikh, 1876) y en turco Hukuk-i beyneddüvel-i kanunu (Istanbul, Vakit Gazetesi Matbaasi, 1879). La más llamativa es la traducción china a cargo del traductor de H. Wheaton a este idioma W.A.P. Martin: Gong fa hui tong (Beijing, Tong wen guan, 1884) ${ }^{71}$. Para Becker Lorca los juristas semi periféricos creaban sus propios tratados con lo que leían de Inglaterra, Alemania y Francia, traducían muchos de ellos, pero luego publicaban sus propios tratados en los idiomas de sus países, de esta forma entregaban un panorama general de la disciplina ${ }^{72}$. El japonés $S$.

Hamburger Kolleg de la Universidad de Bonn. [visible en internet:www.recht-als-kultur.de/].

68 Pocock, John, Momento Maquiavelo: El pensamiento politico florentino y la tradición republicana atlántica (trad. cast., Madrid, 2002). SKINNER, Quentin, Visions of Politics, Vol I: Regarding Method (Cambridge, 2002).

${ }^{69}$ D'Aspremont, Jean, The professionalization of international law, en D'Aspremont, Jean; Gazzini, Tarcisio; Nollkaemper, Andre y Werner, Wouter (eds.), International law as a profession (Cambridge, 2017), pp. 21-22. Peters, Anne, The Rise and Decline of the International Rule of Law and the Job of Scholars, en Heidelberg: Max Planck Institute for Comparative Public Law \& International Law (MPIL) Research Paper, 16 (2017).

${ }^{70}$ Duve, Thomas, Von der Europäischen Rechtsgeschichte zu einer Rechtsgeschichte Europas in globalhistorischer Perspektive, en Zeitschrift des Max-Planck Instituts für europäische Rechtsgeschichte, 20 (2012). Para el caso del alemán Heineccius en Sudamérica: Pérez Godoy, Fernando, Johannes Heineccius y la historia transatlántica del ius gentium, en Revista Chilena de Derecho, 44/2 (2017), pp. 539-562.

${ }^{71}$ Datos extraídos de BeCKer LorCA, Arnulf, Mestizo International Law A Global Intelectual History 1842-1933 (Cambridge, 2015), p. 129.

72 Véase esta tarea de traductor de la normatividad internacional a espacios locales en el 
Takahashi produjo su propio manual en japonés Heiji kokusaihõrom (Tokyo, Nihon Daigaku, 1907) en base a esta metodología. Las traducciones del derecho de gentes en China se dan entre 1839 y 1894, precisamente por dos escuelas de traductores del derecho gentes la Tongwenguan de Beijín y la Jiangmna Arsenal de Shanghái. En 1839 y 1847 el primer texto en ser traducido es el de Vattel Le Droit de gens, que llevó por título Geguo lüli y fue realizado por la escuela de Yuan y su traductor fue Parker. En el 47 aparece con el nombre de in Haiguo tuzhi. En 1846 es traducido el texto de Wheaton Elements of international law por la escuela de Tongwenguan a cargo del misionero americano William A. P. Martin. El título de Wheaton fue Wonguo gongfa. En 1876 el texto Le guide diplomatique de Charles de Martens aparece bajo el nombre Xyngzao zhizang también por Martin en la escuela de Tongwenguan. Finalmente, en 1880 Bluntschli y su Das moderne Völkerrecht aparece como Gongfa huitong ${ }^{73}$.

\section{GIRO IMPERIAL}

Iniciada por Koskenniemi, Tuck, y Armitage en los 90's pero con raíces en el movimiento americano de Third World Approaches to International Law (TWAIL) y los estudios poscoloniales en general, el giro imperial de la historia del derecho internacional constituye un cambio de paradigma rupturista con el orden libera $7^{74}$. En Francia resaltan los nombres de Tourme-Jouannet, Ruiz Fabri, Toufayan, An introduction to the History of Law of Nations in the East Indies de C. H. Alexandrowicz, recientemente republicada, es una colección de estudios pioneros del desarrollo del derecho internacional en espacios extra europeos, lo que demuestra el mismo interés en el giro histórico imperial del derecho internacional. R. P. Anand, T. O. Ellias, N. Singh, y Gathii son frecuentemente notados también como precursores de la actual perspectiva ${ }^{75}$. Si quisiéramos resumir, esta metodología parte de las preguntas: ¿cuánto de política y cuánto de jurídico hay en el ius gentium?, ¡el derecho internacional es sinónimo justicia universal, paz global, buena gobernanza, integración de mercados, seguridad internacional o por el contrario instrumento de poder e intervención de los Estados poderosos en favor de intereses coloniales e imperialistas? ${ }^{76}$ Sabemos que estas preguntas

caso de Bello: Fiocchi Malaspina, Elisabetta y Keller-Kemmerer, Nina, International Law and Translation in the 19th century, en Zeitschrift für europäische Rechtsgeschichte Rg., 22 (2014).

${ }^{73}$ Kroll, Sebastian, Normgenese durch Re-Interpretation China und das europäische Völkerrecht im 19. und 20. Jahrhundert (Baden-Baden, 2012), p. 15.

${ }^{74}$ Koskenniemi, Martii, From Apology to Utopia. The Structure of International Legal Argument (Cambridge, 2005). KosKenNIEMI, Martii, Histories of International law: Dealing with Eurocentrism, en Zeitschrift des Max-Planck Instituts für europäische Rechtsgeschichte, 19 (2011). TucK, Richard, The Rights of War and Peace (Oxford, 2001). Armitage, David, Foundations of Modern International Thought (Cambridge, 2013).

75 AnAND, Ram Prakash, New States and International Law (Delhi, 1972). Elias, Olufemi, New Horizons in International Law (Alphen aan den Rijn, 1979). SingH, Nagendra, India and International Law: Ancient and Medieval (New Delhi, 1969). SINHA, Prakash, New Nations and the Law of Nations, (Leyd, 1967).

${ }^{76}$ Moser, Carolyn, Das Völkerrecht-ein Garant firr Frieden, Sicherheit und Gerechtigkeit?, en 
atraviesan la historia del derecho internacional, viejas querellas entre idealistas y realistas. Para los historiadores críticos del legado jurídico de Europa, el derecho internacional es imperialista y animado fundamentalmente por la idea de misión como elemento fundamental de expansión. Muchas etiquetas aparecen reiteradas: el derecho internacional es una institución corrupta, un instrumento de dominación, control ilegítimo, etc.

Anthony Anghie, tal vez en el estudio más paradigmático de la década de los 90', formulaba que el derecho internacional trabaja con la lógica de la diferencia civilización/barbarie lo que es una persistente herencia colonial del siglo XIX ${ }^{77}$. Seguramente este ataque es el más común a la historiografía clásica del derecho internacional ${ }^{78}$. Para Anghie, así Steiger, desde Vitoria en adelante se sostendría una diferencia cultural entre Estados europeos, civilizados, cristianos y desarrollados frente a lo s o t r o s ${ }^{79}$. El siglo XIX, especialmente por las experiencias coloniales e imperiales europeas, habría sido clave para la configuración del actual entendimiento del orden normativo internacional, fue en este siglo cuando adquirió su universalidad y la profesión de internacionalista se difundió por el mundo. El giro imperial indica que esta universalización no fue consecuencia de un diálogo cosmopolita transcivilizacional en términos de Onuma ${ }^{80}$, sino resultado del proceso de expansión imperial europea. Si nuestro entendimiento del derecho internacional es hasta hoy eminentemente europeo, explica Anghie, es porque la expansión imperial del viejo continente arrastró a una serie de pueblos -africanos, asiáticos, americanos- a un sistema de derecho nacido de la cultura y experiencia histórica europea ${ }^{81}$. Este es el conocido o r íg e n c o l o n i a l del derecho internacional.

Siguiendo a Anghie, el derecho internacional no se convirtió en universal porque fue impuesto por poderes europeos en un contexto imperial, más bien fue consecuencia de la confrontación europea -mayormente cultural- con naciones viviendo en la periferia. La colisión de Estados europeos con pueblos no europeos, también llamado colonial encounter, determinó para Anghie el concepto europeo de soberanía, el cual dominó el sentido del derecho internacional en el tercer mundo y sirvió para excluir e incluir al resto de naciones no europeas ${ }^{82}$. El concierto internacional regulado por los grandes poderes entregó membresía a las naciones no occidentales para ser parte de la normatividad del derecho internacional pero siempre dependiendo de ciertos requisitos no solo jurídicos, esto es, la mencionada capacidad de reciprocidad constitucional, sino también políticos,

Vortrag im Rahmen der Themenkonzerte, Max Planck Institut für Internationales Recht, 15 (2014).

77 ANGHIE, Antony, Finding the Peripheries: Sovereignty and Colonialism in Nineteenth-Century International Law, en Harvard International Law Journal, 40 (1999). ANGHIE, Antony, Imperialism, Sovereignty and the Making of International Law (Cambridge, 2004).

78 Chimni, Bhupinder, cit. (n. 57), p. 36.

79 ANGHIE, Antony, Finding, cit. (n. 77), p. 5.

${ }^{80}$ OnUMA, Yasuaki, A transcivilizational perspective on international law, questioning prelevant cognitive frameworks in the emerging multi-polar and multi-civilizational world of the twenty-first century (Leiden, 2010).

81 Anghie, Antony, Finding, cit. (n. 77), p. 2.

82 VAN DER Linden, Mieke, The acquisition of Africa (1870-1914) (Leiden, 2017), p. 9. 
económicos, sociales y sobre todo culturales ${ }^{83}$. Pero Tourme Jouannet indica que no solo la distinción en base a un criterio cultural determinó la personalidad jurídica de las naciones extra europeas, sino directamente categorías étnico raciales que configuraron el derecho internacional del siglo XIX, transformándolo en el siglo XX en un instrumento de reconocimiento unilateral, asimilación forzada y uniformización al derecho occidental como ocurrió, por ejemplo, con las elites ilustradas en Japón y China ${ }^{84}$. En efecto, el relato, los términos, las historias y tecnicismos son todos de origen europeo, nacen del mercado cultural de las elites europeas para comunicarse con otras elites del mundo. Es un medio en el que Europa es idealizada y definida por los términos soberanía, capitalismo, modernidad, Estado de derecho, etc marcando así el horizonte de la imaginación profesional hasta nuestros días.

Esta perspectiva ha alimentado la investigación de la historia de los encuentros, pero sobre todo los estudios críticos del derecho internacional. Prueba de lo anterior es el movimiento de Third World Approach to International Law (TWAIL) ${ }^{85}$. Como aclaran Chimni y Anghie, esta tendencia advierte precisamente que el derecho internacional solo tendría sentido en el contexto de la historia vivida por pueblos del tercer mundo ${ }^{86}$, esto es, en contexto de colonización y descolonización, siendo objetivo de sus investigadores pioneros -Georges AbiSaab, García- Amador, Mohammed Badjaoui y Taslim O. Elias- transformar el derecho internacional de un lenguaje de opresión a uno de emancipación ${ }^{87}$. Tópicos recurrentes son en este sentido el análisis de tratados desiguales impuestos por potencias, soberanías fallidas o medias, protectorados, mandatos, estatutos coloniales, capitulaciones en favor de Occidente, etc. Los planteamientos de TWAIL, en los que se incluye también los Critical Legal Studies (CLS) y parte de los estudios postcoloniales de Said, Ghandi, Babha, Chakrabarty inter alias ${ }^{88}$, ponen además el acento en el eurocentrismo propio de la ciencia internacionalista, así como el carácter estratégico y funcional del derecho internacional sometido a intereses económicos y geopolíticos.

Koskenniemi, Rech y Jiménez Fonseca, principalmente desde los programas de investigación del Erik Castrén Institute of International Law and Human Rights de la Universidad de Helsinki, han resaltado no solo la directa relación entre el desarrollo de derecho internacional e imperialismo, colonialismo y eurocentris-

${ }^{83}$ Bowden, Brett, The Colonial Origins of International Law. European Expansion and the Classical Standard of Civilization, en Journal of the History of International Law, 7/1 (2005).

${ }^{84}$ Tourme -Jounnnet, Emmanuelle, What is a Fair International Society? (Oxford, 2013), pp. 106-110.

${ }^{85}$ PiCHL, Maximilian, Die Verrechtlichung der Welt-Ansätze einer postkolonialen Rechtstheorie, en Kritische Justiz, 45 (2012). OKAFOR, Obiora Chinedu, Critical Third World Approaches to International Law (TWAIL): Theory, Methodology, or Both?, en International Community Law Review, 10 (2008), pp. 371-378.

${ }^{86}$ Anghie, Antony y CHImni, Bhupinder, Third World Approaches to International Law and Individual Responsability in International Conflicts, en Chinese JIL, ( 2003), p. 78.

87 Ibíd., pp. 79-80.

${ }^{88}$ SAID, Edward, Orientalism (Penguin, 1978). BНABHA, Homi K. The Location of Culture (London, 1994). 
mo. Jiménez Fonseca también denuncia la implicación de la extensión de esta normatividad sobre la explotación de recursos naturales y destrucción del medio ambiente en el continente americano desde su descubrimiento y conquista ${ }^{89}$. Para Koskenniemi los actores no europeos negociaron en términos de imperial rules y por tanto participaron en configurar las características de los imperios en contextos particulares ${ }^{90}$. El crítico acercamiento al derecho internacional y a organizaciones internacionales como la Liga de las Naciones como una imposición hegemónica de Occidente o como instrumento de facto de soberanías hace, así Koskenniemi, de la historia del derecho internacional una historia de centros imperiales sucediendo unos a otros en su esfuerzo por dominar al resto del mundo. Esta mirada crítica considera además la expansión del derecho internacional no como triunfo de los derechos humanos, del rule of law sobre las relaciones de poder y la influencia de juristas humanistas cosmopolitas como Gentili, Grotius, Vattel y Westlake ${ }^{91}$. Por mucho tiempo, indica Koskenniemi, la historia del derecho internacional se concentró en las grandes ideas o teleologías como la de la paz perpetua o el fin de la esclavitud, pero no se cuestiona el derecho internacional privado -derecho comercial internacional- porque no tiene una naturaleza política ${ }^{92}$. Koskenniemi llama en este sentido a mirar el background del derecho internacional ${ }^{93}$, precisamente al sistema bancario y crédito que acompaña al proceso de acumulación y al desarrollo del comercio global los cuales tienen escaso espacio en la historia del derecho internacional. Por ejemplo, para el jurista finlandés la historia del derecho internacional también se hizo -o se encuentra- en el estudio de la Caroline Company de la cual John Locke era su secretario y uno de sus sostenedores. Si una gran cantidad de trabajos en la historia intelectual había buscado en Grocio al padre del derecho internacional moderno, resaltando una primera regulación internacional en conflictos armados y por tanto valorando el espíritu humanista y cosmopolita de su obra, otros como van Ittersum, Straumann y el mismo Richard Tuck han develado la íntima conexión entre la aparición de De iure belli ac pacis

89 Jiménez Fonseca, Manuel, The Colonization of American Nature and the Early Developments of International Law, en Journal of the history of international law, 12 (2010) pp. 189-225.

90 Koskenniemi, Martti, Preface, en Él mismo (ed.), International law and empire (Oxford, 2016), p. viii.

${ }^{91}$ Ibíd., p. 4.

92 Dupuy resalta los avances del derecho internacional en ámbitos de justicia internacional, estandarización de protección derechos humanos, ius cogens, así como el hecho que han sido los mismos países del tercer mundo quienes han creado jurisprudencia y las normas del derecho internacional creadas por el sur contra el occidente como ius cogens han sido recogidos en distintas convenciones internacionales. DupuY, Pierre-Marie, Some Reflections on Contemporary International Law and the Appeal to Universal Values: A Response to Martti Koskenniemi, en The European Journal of International Law, 16/1 (2005), pp. 134-136. Una respuesta en: OBREGÓN, Lilian, Martti Koskenniemi's critique of Eurocentrism in international law, en WERnER, Wouter y De HoOn, Marieke y GaLÁn, Alexis (eds.), The law of international lawyers: reading Martti Koskenniemi (Cambridge, 2017).

93 Así, en el siglo XIX tiene lugar: "the European occupation and government of uncivilized territories and in the formation of European extraterritoriality and consular jurisdiction regimes in China, Japan, the Middle East”. KosKenNiEMI, Martii, cit. (n. 90), p. 9. 
y los intereses expansionistas asiáticos de la Dutch East India Company (VOC) ${ }^{94}$. Igual caso para la intervención europea en el imperio otomano como demuestra Davide Rodogno y Richard Potz ${ }^{95}$, o las investigaciones sobre el Scramble for Africa (1870-1914) mediante el estudio del derecho colonial y consular según el mencionado estudio de Van der Linde.

Apoyados en los avances de la historia cultural, el recurso de la contextualización y sobre todo desde los estudios postcoloniales, figuras o espíritus u n i v e r s a l e s como Locke, Grocio o Pufendorf son hoy puestos bajo crítica por el marcado euro y Estado-centrismo de sus obras ${ }^{96}$. Para Koskenniemi los mencionados teóricos europeos fueron al mismo tiempo juristas profesionales que sirvieron a los intereses coloniales e imperiales de sus respectivos clientes. En la mirada de Koskenniemi la reflexión histórica debe entonces recaer en el background de las normas de derecho privado o lo que él denomina como empire of private law ${ }^{97}$. Para el finlandés se debe resaltar en consecuencia que la expansión jurídica de Europa fue principalmente dirigida por operadores privados, compañías coloniales como la mencionada Dutch East Company o The India England Company $^{98}$, siendo el pensamiento jurídico internacionalista solo un manto o fachada de legitimidad. En este sentido, el foco investigativo debería estar más en los contratos privados, en las capitulaciones, en los derechos de propiedad privada, que en el rol tradicional de la soberanía y Estado moderno, es decir, en el derecho público europeo. Koskenniemi ve finalmente el desarrollo del derecho internacional del siglo XIX más en los contratos desiguales entre inversores, especuladores financieros, compañías privadas, mercantes, más que en el descrito sistema westfaliano y el proceso de formación del Estado ${ }^{99}$.

Sintetizando, para los estudios postcoloniales el desarrollo del derecho internacional en el XIX no sería por tanto un antídoto para combatir el poder desregulado del colonialismo, la expansión territorial y totalitarismos (sociedad internacional anárquica). A partir de The Gentle Civilizer of Nations de Koskenniemi se desprende que la historia del derecho internacional del siglo XIX, marcada por el positivismo y liberalismo, no fue concebido como un proyecto legal universal

\footnotetext{
${ }^{4}$ Straumann, Benjamin, Roman Law in the state of nature. The Classical Foundations of Hugo Grotius'Natural Law (Cambridge, 2015).

${ }_{95}$ Potz, Richard, Islamisches Recht und europäischer Rechtstransfer, en Europäische Geschichte Online, (2011). Rodogno, Davide, European Legal Doctrines on Intervention and the Status of the Ottoman Empire within the 'Family of Nations' Throughout the Nineteenth Century, en Journal of the History of International Law, 18 (2016).

96 Hunter, Ian, Spatialisation of Justice in the Law of Nature and Nations: Pufendorf, Vattel, and Kant (Queensland, 2008). Cavallar, Georg, Vitoria, Grotius, Pufendorf, Wolff and Vattel: Accomplices of European Colonialism and Exploitation or True Cosmopolitans, en Journal of the history of International Law, 10 (2008), pp. 181-209. KosKENNIEMI, Martti, Empire and International Law: The Real Spanish Contribution, en The University of Toronto Law Journal, 61/1 (2011), pp. 1-36.

${ }^{97}$ KoskenNiemi, Martii, cit. (n. 90), p. 17.

${ }_{98}$ "But much of Europe's expansion took place through private operators, colonial or trading companies, and by way of private contract and the exercise of the right of private property". KosKENNIEMI, Martii, cit. (n. 90), p. 10.

99 Koskenniemi, Martii, cit. (n. 90), p. 14.
} 
humanista ${ }^{100}$. Su ingreso no garantizaría un International Rule of Law y no tendría por tanto una fundación axiológica objetiva. La teoría del derecho internacional aparece en Koskenniemi como un lenguaje subjetivo con una gramática específica y determinada por los intereses de los teóricos europeos del derecho de gentes condicionados por las circunstancias económicas, sociales, políticas y culturales del siglo XIX. Koskenniemi quiebra con el universalismo de la historia canónica del derecho internacional y la teoría liberal de las relaciones entre los Estados. Para ello plantea como base la teoría deconstructiva estructuralista, la cual une a argumentos del linguistic turn, la crítica postcolonial, la semiótica de Saussure y la filosofía de Wittgenstein y Honnet (Frankfurter Schule). Koskenniemi se pregunta por la normativa desmitificada, revelando las circunstancias de su origen ${ }^{101}$. Su escepticismo en el proyecto internacionalista lo lleva además a indagar qué hay detrás del argumento profesional, cuál es el origen del discurso ${ }^{102}$, aquello detrás de la convencionalidad, la formalidad y lo oficial ${ }^{103}$. Planteamientos parecidos se leen en la obra de Monique Chemillier y la doctrina francesa de análisis crítico desarrollado por la Escuela de Reims ${ }^{104}$. M. Miaille ${ }^{105}$ y los coloquios de Charles Chaumont, explica la jurista francesa, se preguntan por la naturaleza obligatoria de las normas que caracterizan al derecho internacional, considerando la perspectiva positivista como insuficiente ${ }^{106}$. El rechazo a explicar la naturaleza del derecho solo a través de la autoridad de las instituciones, lleva a la doctrina Reims a ver detrás del mecanismo legal. Su objetivo es ir derribando la imagen del positivismo de un campo del derecho como espacio cerrado y más bien explorando en la sociedad, sus contradicciones y el rol de las fuerzas sociales para producir una norma ${ }^{107}$. Esto conllevaba el análisis de la producción dialéctica de normas a partir de sus condiciones concretas de formación. Chemillier cita en este sentido textualmente a Böckenförde para quien el fundamento del derecho sería también parte del derecho. Por ello, para Chemillier no puede analizarse la norma internacional fuera de su contexto o estado de contradicciones sociales de un punto determinado en el tiempo ${ }^{108}$.

${ }^{100}$ Koskenniemi, Martti, The gentle civilizer of nations. The rise and fall of modern international law, 1870-1960 (New York, 2004).

101 Koskenniemi, Martii, cit. (n. 90), p. 6.

102 "Might history illuminate the ways in which law has been used in the past to structure, support, channel, and oppose international power?’. KosKenNIEMI, Martti, What should international legal history become?, en Kadelbach, Stefan et al. (eds.), System, Order cit. (n. 2), p. 382.

103 Bourdieu, Pierre, Über den Staat. Vorlesungen am Collège de France 1989-1992 (trad. alem., Berlin, 2014).

104 Chemillier-Gendreau, Monique, Humanité et souverainetés Essai sur la fonction du droit international (Paris, 1995).

105 Miaille, Michele, Introduction critique au droit (Paris, 1977).

106 Chemillier-Gendreau, Monique, Contribution of the Reims School to the Debate on the Critical Analysis of International Law: Assessment and Limits, en The European Journal of International Law, 22/3 (2011), p. 651

107 "French critical doctrine refused to stay inside a zone which was arbitrarily qualified as law by solely institutional references". CHEMILLIER-GENDREAU, Monique, cit. (n. 106), p. 651.

108 "Hence it is possible to conclude that law and proclaimed norms operate within the framework of social contradictions. Even if they are not directly applied, the existence of proclaimed norms 


\section{CONCLUSIÓN}

Las categorías y planteamientos metodológicos descritos arriba, en un intento de sistematización y divulgación, son necesarios para repensar el estado de la ciencia jurídica internacional en Chile, específicamente en nuestro caso con la historia del derecho internacional. La desmitificación, des europeización y deconstrucción de muchos de los planteamientos básicos de esta disciplina a nivel académico global son necesarios de aplicar en nuestro medio desde la valoración del recurso histórico. Así, hemos pretendido abrir vías de interpretación para poder repensar no solo el derecho internacional desde lo global, sino repensar aquel orden normativo que existía fuera del orden jurídico internacional europeo al cual el Estado de Chile se fue haciendo parte desde inicios de su vida independiente. Será objetivo de futuras investigaciones saber si la adopción, domesticación o translation del orden normativo europeo westfaliano, conocido en el siglo XIX bajo el rótulo de leyes civilizadas del mundo, completó la civilización en términos de Obregón ${ }^{109}$, esto es, consumó la universalización de la ciencia europea del derecho internacional en nuestro medio, o creó una normatividad híbrida como postula Becker Lorca, o si más bien fuimos en nuestra lejanía parte de las redes continentales hemisféricas de transmisión de conocimiento que plantea Scardi ${ }^{110}$, o simplemente primaron las relaciones de poder y fuerza en la relación de paz y guerra con nuestros vecinos. Si como Onuma establece, no existe un concepto unitario -westfaliano- del derecho internacional a la luz de la historia global y más bien tenemos una multiplicidad y pluralidad de órdenes normativos en distintas regiones ${ }^{111}$, ligados a actores, costumbres y tradiciones propias de cada cultura jurídica, habremos de descubrir un sinnúmero de nuevas h i s $\mathrm{t}$ o $\mathrm{r}$ i a s del derecho internacional ${ }^{112}$. En ellas aparecen hoy a nivel global nuevas ideas del derecho internacional pero también se validan otras ideas de justicia, imágenes del mundo, procedimientos, formalismos, tecnicismos propios de cada civilización. La contextualización tiene esa finalidad, contextualizar los conceptos y textos. Este es el primer paso según Steiger para alcanzar una historia global del derecho internacional, pero con la advertencia de no concentrarse solo en el contexto imperial y colonial, sino en todo contexto que marque la coexistencia de culturas y civilizaciones ${ }^{113}$. La cultura es la primera fuente de normatividad, por ello la tarea de importantes centros internacionales de historia del derecho como los nombrados es justamente ir detrás de las culturas del Asia, China, India, mundo islámico, así como pueblos originarios

plays a role in social movement and permits certain contradictions to be overcome more quickly". Chemillier-Gendreau, Monique, cit. (n. 106), p. 655.

109 Obregón, Lilian, Completing civilization: Creole consciousness and international law in nineteenth-century Latin America, en ORFORD, Anne (ed.), International Law and its Others (Cambridge, 2006).

110 SCARFI, Juan Pablo, The hidden history of international law in the Americas (New York, 2017).

111 Onuma, Yasuaki, cit. (n. 80), p. 266.

112 STEIGER, Heinhard, cit. (n. 35), pp. 84-85.

${ }^{113}$ Ibíd., p. 87. 
pre-coloniales, develar sus órdenes normativos originales, para luego reconstruir una normatividad post eurocéntrica, transcivilizacional y global.

\section{BiBLIOGRAFÍA}

Anand, Ram Prakash, New States and International Law (Delhi, 1972).

Anghie, Antony, Finding the Peripheries: Sovereignty and Colonialism in NineteenthCentury International Law, en Harvard International Law Journal, 40 (1999).

ANGHIE, Antony, Imperialism, Sovereignty and the Making of International Law (Cambridge, Cambridge University Press, 2004).

Anghie, Antony y Chimni, Bhupinder, Third World Approaches to International Law and Individual Responsability in International Conflicts, en Chinese JIL, (2003).

Annino, Antonio; Castro Leiva, Luis y Guerra, François-Xavier (eds.), De los imperios a las naciones: Iberoamérica (Zaragoza, IberCaja-Forum Internacional des Sciences Humaines, 1994).

Armitage, David, Foundations of Modern International Thought (Cambridge, Cambridge University Press, 2013).

BнавнA, Homi K. The Location of Culture (New York, Routledge, 1994).

BeCKer LorCA, Arnulf, Mestizo International Law A Global Intelectual History 18421933 (Cambridge, Cambridge University Press, 2015).

Bello, Andrés, Principios de derecho de jentes (Valparaíso, 1832).

BENTON, Lauren y FORD, Lisa, Rage for Order. The British Empire and the Origins of International Law 1800-1850 (Cambridge, Mass., London, Cambridge University Press, 2016).

BÖDEKER, Hans Erich von, Strukturen der deutschen Frühaufklärung 1680-1720 (Göttingen, Vandenhoeck \& Ruprecht, 2008).

Bourdieu, Pierre, Über den Staat. Vorlesungen am Collège de France 1989-1992 (trad. alem., Berlin, Suhrkamp, 2014).

Bowden, Brett, The Colonial Origins of International Law. European Expansion and the Classical Standard of Civilization, en Journal of the History of International Law, 7/1 (2005).

BURKHARDT, Johannes, Wars of States or Wars of Stat-Formation?, en AsBACH, Olaf y SCHRÖDER, Peter (eds.) War, the State and International Law in Seventeenth-Century Europe (Farnham, Ashgate, 2010).

CASSESE, Antonio, States: Rise and Decline of the Primary Subjects of the International Community, en Fassbender, Bardo y Peters, Anne (eds.), The Oxford Handbook of International Law (Oxford, Oxford University Press, 2012).

Carpintero Benítez, Francisco, Nuestros prejuicios acerca del llamado derecho natural, en Persona y Derecho: Revista de Fundamentación de las Instituciones Jurídicas y de Derechos Humanos, 27 (1992).

Cavallar, Georg, Vitoria, Grotius, Pufendorf, Wolff and Vattel: Accomplices of European Colonialism and Exploitation or True Cosmopolitans, en Journal of the history of International Law, 10 (2008).

Chakrabarty, Dipesh, Provincializing Europe. Postcolonial Thought and Historical Difference (Princeton, Princeton University Press, 2008).

Chemillier-Gendreau, Monique, Contribution of the Reims School to the Debate on the Critical Analysis of International Law: Assessment and Limits, en The European Journal of International Law, 22/3 (2011). 
Chemillier-Gendreau, Monique, Humanité et souverainetés Essai sur la fonction du droit international (Paris, éditions la découverte, 1995).

Chimni, Bhupinder, Le passé, le présent et Lávenir du droit international, en Oufayan, Mark (ed.), Droit international et nouvelles approches sur le tiers-monde: entre répétition et renouveau (Paris, Société de législation compare, 2013).

Craven, Matt, Introduction: International Law and Its Histories, en ÉL MISMO; FITZMaurice, Malgosia y Vogiatzi, Maria (eds.) Time, History and International Law (Boston, Leiden, Brill, 2007).

D'Aspremont, Jean, The professionalization of international law, en D'Aspremont, Jean; GazZini, Tarcisio; Nollkaemper, Andre y Werner, Wouter (eds.), International law as a profession (Cambridge, Cambridge University Press, 2017).

Derman, Joshua, Carl Schmitt on land and sea, en History of European Ideas, 37 (2011).

Dilthey, John. W., Hombre y mundo en los siglos XVI y XVII (trad. cast., México, Fondo Cultura Económica, 1978).

DuchHardt, Heinz y SChnettger, Matthias, Barock und Aufklärung (5ª ed., Göttingen, Oldenbourg, 2015).

DuchHARDt, Heinz, 1648 - Das Jahr der Schlagzeilen. Europa zwischen Krise und Aufbruch (Köln / Weimar / Wien, De Gruyter, 2015)

DuchHARDT, Heinz, Época del absolutismo (trad. cast., Madrid, Alianza,1992)

Dupuy, Pierre-Marie, Some Reflections on Contemporary International Law and the Appeal to Universal Values: A Response to Martti Koskenniemi, en The European Journal of International Law, 16/1 (2005).

Duve, Thomas, Von der Europäischen Rechtsgeschichte zu einer Rechtsgeschichte Europas in globalhistorischer Perspektive, en Zeitschrift des Max-Planck Instituts für europäische Rechtsgeschichte, 20 (2012).

—Was ist "Multinormativität"? - Einführende Bemerkungen, en Rechtsgeschichte - Legal History Rg., 25 (2017) [visible en internet://dx.doi.org/10.12946/ rg25/088-101].

ELIAS, Olufemi, New Horizons in International Law (Alphen aan den Rijn, 1979).

EsPenhorst, Martin y DuCHHARDT, Heinz (eds.), Frieden übersetzen in der Vormoderne. Translationsleitungen in Diplomatie, Medien und Wissenschaft (Göttingen, Vandenhoeck \& Ruprecht, 2012).

FASSBENDER, Bardo y PeTERs, Anne, The Oxford Handbook of the History of International Law (Oxford, Oxford University Press, 2012).

FernÁNdez SebAStián, Javier (ed.), La aurora de la libertad. Los primeros liberalismos en el mundo iberoamericano (Madrid, Marcial Pons, 2012).

Fiocchi Malaspina, Elisabetta y Keller-Kemmerer, Nina, International Law and Translation in the 19th century, en Zeitschrift für europäische Rechtsgeschichte Rg., $22(2014)$.

FreIST, Dagmar y AsCH, Ronald G, Staatsbildung als kultureller Prozess Strukturwandel und Legitimation von Herrschaft in der Frühen Neuzeit (Wien, Böhlau Verlag, 2005).

GIERKE, Otto, Natural Law and the Theory of Society 1500 to 1800 (trad. ingl., Boston, Beacon Press, 1960).

Grotius, Hugo, De iure belli ac pacis libri tres (Paris, 1625).

Haggenmacher, Peter, Avant propos, en Kadelbach, Stefan; Kleinlein, Thomas y Roth-Isigkeit, David (eds.), System, Order, and International Law: The Early History of International Legal Thought from Machiavelli to Hegel (Oxford, Oxford University Press, 2017). 
HaAkOnssen, Knud, Natural law and moral philosophy: from Grotius to the Scottish Enlightenment (Cambridge, Cambridge University Press, 1996).

Hammerstein, Notker y Stolleis, Michael (eds.), Große Staatsdenker in der frühen Neuzeit. München (München, Beck, 1995).

HeLD, David, La democracia y el orden global del Estado moderno al gobierno cosmopolita (trad. cast., Barcelona, Paidos, 1997).

Hinojosa y Naveros, Eduardo, Los precursores españoles de Grocio (Madrid, Tipografía de Archivos Olózaga, 1930).

Hochstrasser, Tim, Natural Law Theories in the Early Enlightenment (Cambridge, Cambridge University Press, 2000).

Horn, Nobert, Einführung in die Rechtswissenschaft und Rechtsphilosophie (München, C. F. Müller, 2012).

Hunter, Ian, Spatialisation of Justice in the Law of Nature and Nations: Pufendorf, Vattel, and Kant (Queensland, Centre for the History of European Discourses, 2008).

Hunter, Ian, The Secularisation of the Confessional State, The Political Thought of Christian Thomasius (Cambridge, Cambridge University Press, 2007).

Ibarra Cifuentes, Patricio, La guerra en cautiverio. Los prisioneros de la Guerra del Pacifico (1879-1884) (Santiago, Legatum, 2017).

JiMÉNEZ FonseCA, Manuel, The Colonization of American Nature and the Early Developments of International Law, en Journal of the History of International Law, 12 (2010).

JOAS, Hans y KNÖBL, Wolfgang, Kriegsverdrängung: ein Problem in der Geschichte der Sozialtheorie (Frankfurt am Main, Suhrkamp, 2008).

Kalterborn von Stachau, Carl, Kritik des Völkerrechts nach dem jetzigen Standpunkte der Wissenschaft (Leipzig, Verlag von Gustav Mayer, 1847).

Kissinger, Henry, Diplomacy (New York, Simon \& Schuster, 1994).

KISSINGER, Henry, World Order: Reflections on the Character of Nations and the Course of History (New York, Penguin, 2014).

Koselleck, Reinhart, Crítica y Crisis. Un estudio sobre la patogénesis del mundo burgués (trad. cast., Madrid, Fondo Cultura Económica, 2007).

Koskenniemi, Martii, From Apology to Utopia. The Structure of International Legal Argument (Cambridge, Cambridge University Press, 2005).

Koskenniemi, Martti, Empire and International Law: The Real Spanish Contribution, en The University of Toronto Law Journal, 61/1 (2011).

Koskenniemi, Martii, Histories of International law: Dealing with Eurocentrism, en Zeitschrift des Max- Planck Instituts für europäische Rechtsgeschichte, 19 (2011).

Koskenniemi, Martti, Preface, en Él MISMO (ed.), International law and empire (Oxford, Oxford University Press, 2016).

KosKenNiemi, Martti, The gentle civilizer of nations. The rise and fall of modern international law, 1870-1960 (New York, Cambridge University Press, 2004).

Kroll, Sebastian, Normgenese durch Re-Interpretation China und das europäische Völkerrecht im 19. und 20. Jahrhundert (Baden-Baden, Nomos, 2012).

LandweHr, Achim, „Normdurchsetzung“ in der Frühen Neuzeit? Kritik eines Begriffs, en Zeitschrift für Geschichtswissenschaft, 48 (2000).

Landwehr, Achim, Diskurs-Macht-Wissen. Perspektiven einer Kulturalgeschichte, Kulturgeschichte des Politischen, en Archiv für Kulturgeschichte, 85 (2003).

Lessaffer, Randall, Peace treaties from Lodi to Westphalia, en Él mismo (ed.), Peace Treaties and International Law in European History (Cambridge, Cambridge University Press, 2004). 
Maureira Pacheco, Max, La tripartición romana del derecho y su influencia en el pensamiento jurídico de la época Moderna, en Revista Estudios Históricos-Jurídicos, 28 (2006).

MeINECKe, Friedrich, Idea de la razón de Estado en la edad moderna (trad. cast., Madrid, Marcial Pons, 1997).

MiAIlLE, Michele, Introduction critique au droit (Paris, F. Maspero, 1976).

Moser, Carolyn, Das Völkerrecht - ein Garant für Frieden, Sicherheit und Gerechtigkeit?, en Vortrag im Rahmen der Themenkonzerte, Max Planck Institut für Internationales Recht, 15 (2014).

NefF, Stephen, Justice among Nations, a history of international law (Cambridge, Cambridge University Press, 2014).

NiCKLas, Thomas, Macht-Politik-Diskurs. Möglichkeiten und Grenzen einer Kulturgeschichte des Politischen, en Archiv für Kulturgeschichte, 86 (2004).

Nuzzo, Luigi, Territory, Sovereignty and the Construction of the Colonial Space, en Koskenniemi, Martti y Rech, Walter y Jiménez FonseCA, Manuel (eds.), International law and empire: historical explorations (Cambridge, Cambridge University Press, 2016).

OBREgÓn, Lilian, Completing civilization: Creole consciousness and international law in nineteenth-century Latin America, en ORFORD, Anne (ed.), International Law and its Others (Cambridge, Cambridge University Press, 2006).

Obregón, Lilian, Martti Koskenniemi's critique of Eurocentrism in international law, en Werner, Wouter; De Hoon, Marieke y Galán, Alexis (eds.), The law of international lawyers: reading Martti Koskenniemi (Cambridge, Cambridge University Press, 2017).

OKAFOR, Obiora Chinedu, Critical Third World Approaches to International Law (TWAIL): Theory, Methodology, or Both?, en International Community Law Review, 10 (2008).

Onuma, Yasuaki, A transcivilizational perspective on international law, questioning prelevant cognitive frameworks in the emerging multi-polar and multi-civilizational world of the twenty-first century (Leiden, Nijhof, 2010).

Oppenheim, Lassa, The Science of International Law: Its Task and Method, en American Journal of International Law, 2 (1908).

Osterhammel, Jürgen, The transformation of the world. A global history of the Nineteenth century (trad. ingl. Princeton, Princeton University Press, 2014).

ORford, Anne, The Past as Law or History? The Relevance of Imperialism for Modern International Law, en IILJ Working Paper 2012/2, U of Melbourne Legal Studies Research Paper, 600 (2012).

PÉrez Godor, Fernando, Ibero-Amerikanische Zirkulation des protestantischen Naturund Völkerrechts im 18. und 19. Jahrhunderts (Göttingen, Sierke Verlag, 2016).

Pérez Godoy, Fernando, Johannes Heineccius y la Historia Transatlántica del Ius Gentium, en Revista Chilena de Derecho, 44/2 (2017).

Peters, Anne, The Rise and Decline of the International Rule of Law and the Job of Scholars, en Heidelberg: Max Planck Institute for Comparative Public Law \& International Law (MPIL) Research Paper, 16 (2017).

PICHL, Maximilian, Die Verrechtlichung der Welt - Ansätze einer postkolonialen Rechtstheorie, en Kritische Justiz 45 (2012).

Pocock, John, Momento Maquiavelo: El pensamiento politico florentino y la tradición republicana atlántica (trad. cast., Madrid, Tecnos, 2002) 
POLACK, Bruno, El último virrey del Perú. Patricio Lynch y la ocupación chilena durante la Guerra del Pacifico (Santiago, Planeta, 2017).

PотZ, Richard, Islamisches Recht und europäischer Rechtstransfer, en Europäische Geschichte Online, (2011).

Rodogno, Davide, European Legal Doctrines on Intervention and the Status of the Ottoman Empire within the 'Family of Nations' Throughout the Nineteenth Century, en Journal of the History of International Law, 18 (2016).

Rodríguez Puerto, Manuel, Modernidad discutida: jurisprudencia frente iusnaturalismo en el siglo XVI (Cádiz, Universidad de Cádiz, 1998).

Ruskola, Teemu, Legal Orientalism. China, The United States, and Modern Law (Cambridge, Cambridge University Press, 2013).

SAID, Edward, Orientalism (Penguin, 1978).

SÁnchez-Blanco, Francisco, La Ilustración y la unidad cultural europea (Madrid, Marcial Pons, 2013).

SCARFI, Juan Pablo, The hidden history of international law in the Americas (New York, Oxford University Press, 2017).

Schмiтt, Carl, Der Nomos der Erde im Völkerrecht des Jus Publicum Europeam (Köln, Greven, 1950).

SinHA, Prakash, New Nations and the Law of Nations (Leyd, Sijthoff, 1967).

SINGH, Nagendra, India and International Law: Ancient and Medieval (New Delhi, S. Chand, 1969).

SkINnER, Quentin, Visions of Politics, I: Regarding Method (Cambridge, Cambridge University Press, 2002).

SteIger, Heinhard, Das ius publicum europaeum und das Andere, a global history approach, en VON ARNAULD, Andreas (ed.), Völkerrechtsgeschichte(n): historische Narrative und Konzepte im Wandel (Berlin, Duncker \& Humblot, 2017).

STEIGER, Heinhard, Rechtliche Strukturen der Europäischen Staatenordnung 1648-1792, en Zeitschrift für ausländisches öffentliches Recht und Völkerrecht (Zä̈RV), (1999).

STEPHAN, Cora, Die deutsche Kriegsangst beginnt mit dem Jahr 1618, en Welt 14.06.2013, [visible en internet: www.welt.de/geschichte/article117121459/Die-deutscheKriegsangst-beginnt-mit-dem-Jahr-1618.html].

STOLLEIS, Michael, Geschichte des öffentlichen Rechts in Deutschland (München, Beck, 1988).

STOLLeIs, Michael, Normdurchsetzung bei Policeyordnungen der frühen Neuzeit, en RuPPERT, Stefan y VeC, Miloš (eds.), Ausgewählte Aufsätze und Beiträge (Frankfurt am Main, Klostermann, 2011).

Straumann, Benjamin, Roman Law in the state of nature. The Classical Foundations of Hugo Grotius'Natural Law (Cambridge, Cambridge University Press, 2015).

Tourme -Jounnnet, Emmanuelle, What is a Fair International Society? (Oxford, Oxford University Press, 2013).

Truyol y Serra, Antonio, La sociedad internacional (Madrid, Alianza, 1994).

TucK, Richard, The Rights of War and Peace (Oxford, Oxford University Press, 2001).

Vallet de Goytisolo, Juan, Metodología de la determinación del derecho (Madrid, Centro de Estudios Ramón Areces, 1994).

Van Creveld, Martin, The Rise and Decline of the State (Cambridge, Cambridge University Press, 1999).

VAN DER Linden, Mieke, The acquisition of Africa (1870-1914) (Leiden, Brill, 2017). 
Van Gelderen, Martin, 'Iustitiam non includo': Carl Schmitt, Hugo Grotius and the Ius Publicum Europaeum, en History of European Ideas, 37 (2011).

Van Gelderen, Martin y Skinner, Quentin (eds.), Republicanism: Republicanism and constitutionalism (Cambridge, Cambridge University Press, 2002).

VATTEL, Emer de, Le droit des gens ou principes de la loi naturelle, appliqués à la conduite \& aux affaires des Nations \& des Souverains (London, 1758).

Walzer, Michael, Tratado sobre la Tolerancia (trad. cast., Barcelona, Tecnos, 1998).

Wilson, Peter, Der Dreißigjährige Krieg: Eine europäische Tragödie, (Stuttgart, Theiss, 2017).

WestPhal, Siegrid, Der Westfälische Frieden (München, Beck, 2015).

Wheaton, Henry, Elements of International Law: With a Sketch of the History of the Science (Philadelphia, Carey, Lea \& Blanchard, 1836).

Williams, George, La reforma radical (trad. cast., Ciudad de México, Fondo Cultura Económica, 2005).

WolfF, Erik, Grosse Rechtdenker der deutschen Geistesgeschichte (Tübingen, J. C. B. Mohr,1951).

Wunderer, Hartmann, Staat und Herrschaft in der Frühen Neuzeit (Stuttgart, Reclam, 2014).

ZWANTZIG, Zacharias, Theatrum praecedentiae (Berlin, 1705). 
